\title{
Comprehensive Analysis and Assessment of the Role of Major Bioactive Compounds Isolated from Justicia Adhatoda Leaves as Potent Antimycobacterial Agents
}

\section{Smita Mishra}

University of Delhi

Varsha Mehra ( $\square$ varsha.mehra@rajguru.du.ac.in )

University of Delhi

\section{Research Article}

Keywords: Justicia adhatoda, quinazoline alkaloids, Nutrient-starved Mycobacterium, phagolysosome fusion, Synergy

Posted Date: December 1st, 2021

DOI: https://doi.org/10.21203/rs.3.rs-1008118/v1

License: (c) (i) This work is licensed under a Creative Commons Attribution 4.0 International License. Read Full License 


\section{Abstract}

Tuberculosis (TB) continues to be one of the world's leading causes of death by the infectious pathogen Mycobacterium tuberculosis, which infects one-third of the global population. The emergence of the COVID19 pandemic made its spread rapid and the treatment task more daunting. With the havoc of infectious disease expansion, traditional medicines have triggered tremendous interest worldwide. However, less availability of scientific evidence still hinders its practical use. In the present study, we evaluated the potential of the traditional medicinal plant, Justicia adhatoda, which has been used to treat respiratory ailments since ancient times. We have successfully isolated and characterized several bioactive compounds viz- Vasicoline, Vasicolinone, Adhatodine, Adhavasine, Aniflorine, and Vasicinone from J. adhatoda plant leaves, including Vasicine as the principal compound, and showed their anti-tubercular activity on nutrient-starved Mycobacterium smegmatis and Mycobacterium bovis. The study also directs their in-vitro and ex-vivo antimycobacterial potential on THP1 macrophages with internalized Mycobacterium. Our study is one of its first kind, where we assessed the synergistic antimycobacterial effect of the isolated compounds with the first-line drug Isoniazid (INH). Their potential role in promoting phagolysosome fusion and apoptosis of M. bovis infected THP1 macrophages is further evaluated.

\section{Introduction}

Modern medicines mitigate chronic illnesses, correct disabling physical conditions, and cure molecular deficiencies, but their treatments are often marred by debilitating and severe side effects. ${ }^{1,2}$ Tuberculosis (TB) is a chronic respiratory disease affecting more than one-fourth of the world population, causing around 2 million deaths every year, which becomes worrisome with the emergence of the global COVID-19 pandemic. International analysts predict a $26 \%$ increase in TB deaths in upcoming years, with additional 1.4 million TB deaths between 2020 and 2025 as a direct consequence of the pandemic. ${ }^{3,4}$

The bacteria responsible for the disease, Mycobacterium tuberculosis, is known for developing resistance against drugs rapidly, due to which the disease eradication is almost impossible, despite several anti-TB medicines at disposal. In the last four decades, two new TB drugs, bedaquiline, and delamanid have become available for MDR-TB and XDR-TB treatment, but resistant cases continue to surge. 5,6 Urgent need for new anti-TB drugs to improve cure rates for primary and drug-resistant TB has led to a renewed interest in plant-based bioactives as a possible medication. Natural and herbal products have caught the interest of global pharmaceutical companies and researchers worldwide to rediscover their potential as the source of safer drug candidates. According to the World Health Organization (WHO), approximately $75 \%$ of the world's population relies on plant extracts as traditional medicines and therapies for treatment. ${ }^{7}$ However, due to a lack of scientific evidence about their pharmacological potential, mainstream therapies are often considered more reliable. ${ }^{8}$ In recent years, natural products from plant sources are being relooked as they are abundant, readily available, cost-effective, have minimal or no side effects, and are beneficial in chronic disease treatment. $^{8-10}$

Justicia adhatoda (L.) Nees vasica (family Acanthaceae) is a shrub widespread throughout Southeast Asia and the Indian subcontinent. It is commonly known as Malabar nut, Vasaka, or Adulsa (the greater 'neem'). 
The plant possesses anti-inflammatory, antispasmodic (bronchodilator), and expectorant properties. ${ }^{11}$ Plant extracts are also traditionally used to treat cold, cough, asthma, and tuberculosis. ${ }^{12,13}$ The ancient Indian saying, "No man suffering from phthisis need despair as long as the Vasaka plant exists," proves the importance of $\mathrm{J}$. adhatoda plant in treating respiratory ailments. ${ }^{8}$ WHO has recognized the properties of $J$. adhatoda in their manual "The Use of Traditional Medicine in Primary Health Care." 14 In North-East India, the "Meitei" community uses plant leaves and inflorescence to cure fever, cough, asthma, and dysentery. They also prepare a variety of cuisines for good digestion and health. ${ }^{15}$ Recent studies on J. adhatoda $L$. plant leaf extracts showed that the plant has broad-spectrum antimicrobial and antifungal against several pathogens such as E. coli, S. epidermidis, E. aerogenes, P. aeruginosa, B. subtilis, Rhizopus, Penicillium notatum, Candida albicans, Cryptococcus neoformans, and Aspergillus flavus. Studies conducted on J. adhatoda $L$. leaf extracts showed anti-tubercular activity for $M$. tuberculosis MDR strains. ${ }^{16-19}$

J. adhatoda L. plant leaves contain alkaloids as major bioactive components, out of which study of vasicine is extensively carried out for drug development purposes. ${ }^{20,21}$ Our previous study on the plant leaf extract of $J$. adhatoda $L$. proved the presence of several bioactive compounds besides vasicine, possessing antimycobacterial activity with low cytotoxic effects. We further found the components to exhibit a synergistic effect with Isoniazid (INH) on M. smegmatis and M. bovis (BCG). ${ }^{22}$ In the present study, we have characterized the isolated active compounds and analyzed their role as antimycobacterial agents on nutrient-starved Mycobacterium smegmatis and Mycobacterium bovis (BCG). The synergistic antimycobacterial effect of the isolated components was further assessed with Isoniazid (INH) on the Mycobacterium. Additionally, we also studied the action of the isolated compounds on BCG-infected THP1 macrophages to analyze their activity on intracellular Mycobacterium.

\section{Results And Discussion}

\section{Bioactive compound isolation and characterization}

Alkaloids isolated from $\mathrm{J}$. adhatoda majorly constituted quinazoline alkaloids, as depicted from our study of the ${ }^{1} \mathrm{HNMR}$ spectrum. We isolated $~ 99 \%$ pure Vasicine, a white-colored powder, and the highest content $(\sim 27 \%)$ amongst the total isolated alkaloids. The purity of Vasicine was confirmed via HPLC, HRMS,

${ }^{1} \mathrm{HNMR}$, and FTIR results. (Table 1) Besides Vasicine, several other fractions of alkaloids were also isolated. They were all subsequently tested for their in-vitro antimycobacterial activity (Data already published). Six of the best fractions, labeled as $2 A, 2 B, 3 A, 3 B, 5 A$, and $5 B$, were selected and subjected to HPLC (Supplementary Figure 1), HRMS (Supplementary Figure 2), and ${ }^{1}$ HNMR (Table 2) analysis for further characterization. The fractions were found to constitute Vasicoline (mw. 291.4) majorly, Vasicolinone (mw. 305.4), Adhatodine (mw. 335.4), Adhavasine (mw. 218.23), Aniflorine (mw. 349.4), and Vasicinone (mw. 202.4), respectively. (Table 1, Supplementary Figure 2) The isolated compounds were quinazoline compounds, confirmed by observing the 1HNMR spectrum, having signature peaks in nitrogen, aromatic, and sugar region. Signature peaks in the ${ }^{1}$ HNMR spectrum are identified and depicted in Table 2. Minor peaks observed in the spectrum were considered trace impurities often seen during isolation. Several functional groups like $-\mathrm{OH},-\mathrm{N}-\mathrm{H}, \mathrm{C}-\mathrm{H}, \mathrm{C}=\mathrm{O}$, and others were recognized from the FTIR results. The molecular 
weight of the isolated fractions was obtained from HRMS in $(\mathrm{M}+\mathrm{H})^{+}$form, further confirming our findings. (Table 2)

Table 1

Description of obtained isolated fractions HPLC peaks and HRMS details.

\begin{tabular}{|c|c|c|c|c|c|c|}
\hline $\begin{array}{l}\text { Fraction } \\
\text { name }\end{array}$ & Compound & IUPAC Name & $\begin{array}{l}\text { PubChem } \\
\text { ID }\end{array}$ & $\begin{array}{l}\text { Exact } \\
\text { Mol. } \\
\text { Wt. }\end{array}$ & $\begin{array}{l}\text { Isolated } \\
\text { Mol. } \\
\text { Wt. }\end{array}$ & $\begin{array}{l}\text { HPLC } \\
\text { peak } \\
(2 \mathrm{ml} / \mathrm{min} \\
\text { flow } \\
\text { rate) }\end{array}$ \\
\hline $2 A$ & Vasicoline & $\begin{array}{l}\mathrm{N}, \mathrm{N}-\text { dimethyl-2-(1,2,3,9- } \\
\text { tetrahydropyrrolo [2,1- } \\
\text { b]quinazolin-3-yl)aniline }\end{array}$ & 626005 & 291.4 & 291.5 & 1.604 \\
\hline 2B & Vasicolinone & $\begin{array}{l}\text { 3-[2- } \\
\text { (dimethylamino)phenyl]-2,3- } \\
\text { dihydro-1H-pyrrolo[2,1- } \\
\text { b]quinazolin-9-one }\end{array}$ & 627712 & 305.4 & 305.5 & 1.077 \\
\hline $3 A$ & Adhatodine & $\begin{array}{l}\text { methyl 2-(methylamino)-5- } \\
\text { (1,2,3,9tetrahydropyrrolo[2,1- } \\
\text { b]quinazolin-3-yl)benzoate }\end{array}$ & 5316460 & 335.4 & 335.6 & 1.527 \\
\hline 3B & Adhavasine & NA & NA & 218.23 & 218.4 & 1.856 \\
\hline $5 \mathrm{~A}$ & Aniflorine & $\begin{array}{l}\text { (3R)-3-[2- } \\
\text { (dimethylamino)phenyl]-3- } \\
\text { hydroxy-5-methoxy-1,2-- } \\
\text { dihydropyrrolo[2,1- } \\
\text { b]quinazolin-9-one }\end{array}$ & 442881 & 351.4 & 351.6 & 2.076 \\
\hline $5 B$ & Vasicinone & $\begin{array}{l}\text { (3S)-3-hydroxy-2,3- } \\
\text { dihydro1H-pyrrolo[2,1-b] } \\
\text { quinazolin9-one }\end{array}$ & 442935 & 202.21 & 202.4 & 1.389 \\
\hline BA & Vasicine & $\begin{array}{l}\text { (3S)-1,2,3,9- } \\
\text { tetrahydropyrrolo[2,1- } \\
\text { b]quinazolin-3-ol }\end{array}$ & 667496 & 188.23 & 188.4 & 1.137 \\
\hline
\end{tabular}


Table 2

FTIR and NMR peak details obtained of isolated fractions.

\begin{tabular}{|c|c|c|c|}
\hline $\begin{array}{l}\text { Fraction } \\
\text { name }\end{array}$ & $\begin{array}{l}\text { Compound } \\
\text { Identified }\end{array}$ & $\begin{array}{l}\text { FTIR peaks } \\
\text { obtained }\end{array}$ & NMR peaks obtained \\
\hline $2 \mathrm{~A}$ & Vasicoline & $\begin{array}{l}3300-3000- \\
\mathrm{NH}, 2000-1650 \\
\text { - CH (aromatic } \\
\text { ring), 1700-1650 } \\
-\mathrm{C}=\mathrm{N}\end{array}$ & $\begin{array}{l}{ }^{1} \mathrm{H} \text { NMR: } \delta 2.15(1 \mathrm{H}, \mathrm{ddt}, J=13.4,8.0,6.7 \mathrm{~Hz}), 2.37(1 \mathrm{H}, \\
\text { dddd, } J=13.4,7.5,6.8,1.7 \mathrm{~Hz}), 2.75(6 \mathrm{H}, \mathrm{s}), 3.42-3.61 \\
(2 \mathrm{H}, 3.50 \text { (ddd, } J=14.4,6.7,1.7 \mathrm{~Hz}), 3.53(\mathrm{ddd}, J=14.4, \\
8.0,6.8 \mathrm{~Hz})), 4.18(1 \mathrm{H}, \mathrm{dd}, J=7.5,6.8 \mathrm{~Hz}), 4.61-4.83(2 \mathrm{H}, \\
4.68(\mathrm{~d}, J=14.2 \mathrm{~Hz}), 4.76(\mathrm{~d}, J=14.2 \mathrm{~Hz})), 6.52-6.70 \\
(2 \mathrm{H}, 6.59(\mathrm{ddd}, J=7.9,7.6,1.2 \mathrm{~Hz}), 6.64(\mathrm{ddd}, J=8.1, \\
1.2,0.5 \mathrm{~Hz})), 6.78-6.93(2 \mathrm{H}, 6.84(\mathrm{ddd}, J=7.9,1.3,0.5 \\
\mathrm{Hz}), 6.86(\mathrm{ddd}, J=7.9,7.5,1.3 \mathrm{~Hz})), 6.95-7.19(2 \mathrm{H}, 7.03 \\
\text { (ddd, } J=8.1,7.6,1.3 \mathrm{~Hz}), 7.13(\mathrm{ddd}, J=8.1,1.3,0.5 \\
\mathrm{Hz})), 7.20-7.34(2 \mathrm{H}, 7.27 \text { (ddd, } J=8.1,7.5,1.3 \mathrm{~Hz}), 7.28 \\
\text { (ddd, } J=7.9,1.3,0.5 \mathrm{~Hz})) .\end{array}$ \\
\hline $2 B$ & Vasicolinone & $\begin{array}{l}3300-3000- \\
\mathrm{NH}, 2000-1650 \\
-\mathrm{CH} \text { (aromatic } \\
\text { ring), } 1750- \\
\mathrm{C}=0,1700-1650 \\
-\mathrm{C}=\mathrm{N}\end{array}$ & 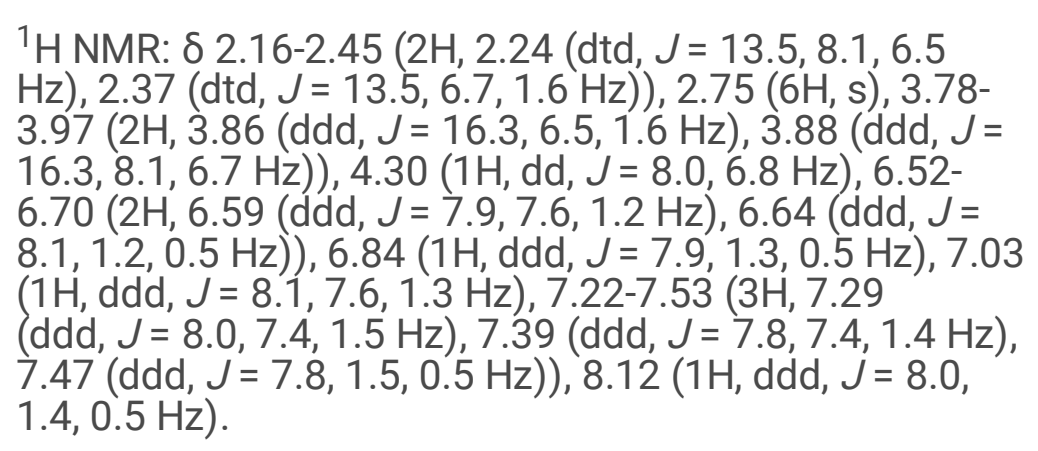 \\
\hline $3 \mathrm{~A}$ & Adhatodine & $\begin{array}{l}3300-3000- \\
\mathrm{NH}, 2000-1650 \\
-\mathrm{CH}(\text { aromatic } \\
\text { ring), } 1700-1650 \\
-\mathrm{C}=\mathrm{N}, 1200- \\
1000-\mathrm{C}-\mathrm{N} \\
3050-\mathrm{OH}, 1755- \\
1700-\mathrm{C}=\mathrm{O}\end{array}$ & $\begin{array}{l}{ }^{1} \mathrm{H} \text { NMR: } \delta 2.05-2.36(2 \mathrm{H}, 2.14(\mathrm{ddt}, J=13.2,8.0,6.7 \\
\text { Hz), } 2.28 \text { (dddd, } J=13.2,7.5,6.8,1.7 \mathrm{~Hz}), 2.56(3 \mathrm{H}, \mathrm{s}), \\
3.42-3.61(2 \mathrm{H}, 3.50(\mathrm{ddd}, J=14.5,6.7,1.7 \mathrm{~Hz}), 3.52 \\
\text { (ddd, } J=14.5,8.0,6.8 \mathrm{~Hz})), 3.81(3 \mathrm{H}, \mathrm{s}), 4.12(1 \mathrm{H}, \\
\text { dd, } J=7.5,6.8 \mathrm{~Hz}), 4.61-4.82(2 \mathrm{H}, 4.68(\mathrm{~d}, J=14.2 \mathrm{~Hz}) \\
4.75(\mathrm{~d}, J=14.2 \mathrm{~Hz})), 6.65(1 \mathrm{H}, \mathrm{dd}, J=7.9,2.6 \mathrm{~Hz}), 6.79- \\
6.95(2 \mathrm{H}, 6.86(\mathrm{ddd}, J=7.9,7.5,1.3 \mathrm{~Hz}), 6.89(\mathrm{dd}, J= \\
7.9,0.5 \mathrm{~Hz})), 7.13(1 \mathrm{H}, \mathrm{ddd}, J=8.1,1.3,0.5 \mathrm{~Hz}), 7.20- \\
7.34(2 \mathrm{H}, 7.27(\mathrm{ddd}, J=8.1,7.5,1.3 \mathrm{~Hz}), 7.28(\mathrm{ddd}, J= \\
7.9,1.3,0.5 \mathrm{~Hz})), 7.45(1 \mathrm{H}, \mathrm{dd}, J=2.6,0.5 \mathrm{~Hz}) .\end{array}$ \\
\hline $3 B$ & Adhavasine & $\begin{array}{l}3300-3000- \\
\mathrm{NH}, 2000-1650 \\
-\mathrm{CH} \text { (aromatic } \\
\text { ring), } 1700-1650 \\
-\mathrm{C}=\mathrm{N}, 3500- \\
3150-\mathrm{OH} \\
\text { (intramolecular), } \\
\text { 1259- }{\mathrm{Ar}-\mathrm{O}-\mathrm{CH}_{3}}\end{array}$ & $\begin{array}{l}{ }^{1} \mathrm{H} \text { NMR: } \delta 2.10-2.36(2 \mathrm{H}, 2.17 \text { (dddd, } J=11.7,6.8,2.2, \\
1.7 \mathrm{~Hz}), 2.27 \text { (dddd, } J=11.7,7.9,7.4,6.8 \mathrm{~Hz}), 2.57(1 \mathrm{H}, \\
\text { ddd, } J=13.6,6.8,1.7 \mathrm{~Hz}), 2.81(1 \mathrm{H}, \mathrm{ddd}, J=13.6,7.9, \\
6.8 \mathrm{~Hz}), 3.81(3 \mathrm{H}, \mathrm{s}), 4.51-4.72(2 \mathrm{H}, 4.58(\mathrm{~d}, J=13.2 \mathrm{~Hz}), \\
4.65(\mathrm{~d}, J=13.2 \mathrm{~Hz})), 5.82(1 \mathrm{H}, \mathrm{dd}, J=7.4,2.2 \mathrm{~Hz}), 6.46- \\
6.60(2 \mathrm{H}, 6.52(\mathrm{dd}, J=7.6,1.5 \mathrm{~Hz}), 6.54(\mathrm{dd}, J=7.9,1.5 \\
\mathrm{Hz})), 7.34(1 \mathrm{H}, \mathrm{dd}, J=7.9,7.6 \mathrm{~Hz}) .\end{array}$ \\
\hline $5 \mathrm{~A}$ & Aniflorine & $\begin{array}{l}3300-3000- \\
\mathrm{NH}, 2000-1650 \\
-\mathrm{CH} \text { (aromatic } \\
\text { ring), } 1754- \\
\mathrm{C}=0,1700-1650 \\
-\mathrm{C}=\mathrm{N}, 3500- \\
3150-\mathrm{OH} \\
\text { (intramolecular), } \\
\text { 1259- }{\mathrm{Ar}-\mathrm{O}-\mathrm{CH}_{3}}\end{array}$ & $\begin{array}{l}{ }^{1} \mathrm{H} \text { NMR: } \delta 2.02(1 \mathrm{H}, \mathrm{ddd}, J=13.9,6.7,1.6 \mathrm{~Hz}), 2.24(1 \mathrm{H}, \\
\text { ddd, } J=13.9,8.1,6.5 \mathrm{~Hz}), 2.81(6 \mathrm{H}, \mathrm{s}), 3.73-4.00(5 \mathrm{H}, \\
3.81 \text { (ddd, } J=15.7,6.5,1.6 \mathrm{~Hz}), 3.91 \text { (ddd, } J=15.7,8.1, \\
6.7 \mathrm{~Hz}), 3.88(\mathrm{~s})), 6.61-6.82(2 \mathrm{H}, 6.67 \text { (ddd, } J=8.1,1.2, \\
0.5 \mathrm{~Hz}), 6.75(\mathrm{ddd}, J=7.8,7.6,1.2 \mathrm{~Hz})), 6.88-7.10(3 \mathrm{H}, \\
6.94(\mathrm{dd}, J=8.5,1.4 \mathrm{~Hz}), 7.01(\mathrm{dd}, J=8.5,7.8 \mathrm{~Hz}), 7.03 \\
\text { (ddd, } J=8.1,7.6,1.4 \mathrm{~Hz})), 7.22(1 \mathrm{H}, \mathrm{dd}, J=7.8,1.4 \mathrm{~Hz}), \\
7.35(1 \mathrm{H}, \mathrm{ddd}, J=7.8,1.4,0.5 \mathrm{~Hz}) .\end{array}$ \\
\hline
\end{tabular}




\begin{tabular}{|c|c|c|c|}
\hline $\begin{array}{l}\text { Fraction } \\
\text { name }\end{array}$ & $\begin{array}{l}\text { Compound } \\
\text { Identified }\end{array}$ & $\begin{array}{l}\text { FTIR peaks } \\
\text { obtained }\end{array}$ & NMR peaks obtained \\
\hline $5 B$ & Vasicinone & $\begin{array}{l}3300-3000- \\
\mathrm{NH}, 2000-1650 \\
-\mathrm{CH}(\text { aromatic } \\
\text { ring), } 1700-1650 \\
-\mathrm{C}=\mathrm{N}, 3500- \\
3150-\mathrm{OH}, \\
1754-\mathrm{C}=\mathrm{O}\end{array}$ & 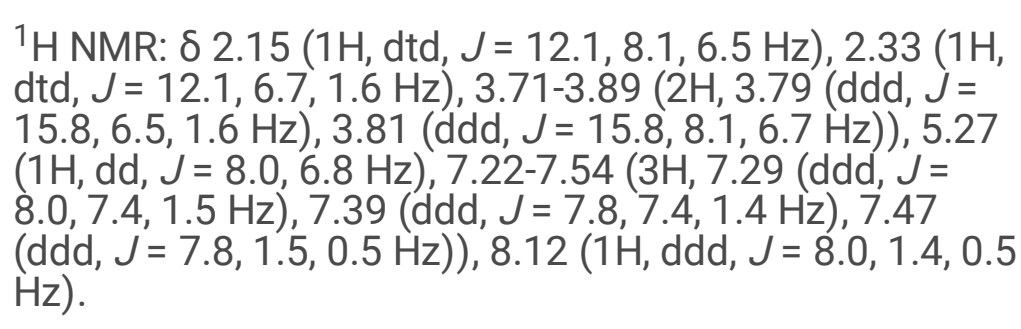 \\
\hline BA & Vasicine & $\begin{array}{l}3300-3000- \\
\mathrm{NH}, 2000-1650 \\
-\mathrm{CH}(\text { aromatic } \\
\text { ring), } 1700-1650 \\
-\mathrm{C}=\mathrm{N}, 3500- \\
3150-\mathrm{OH}\end{array}$ & $\begin{array}{l}{ }^{1} \mathrm{H} \text { NMR: } \delta 2.02-2.19(2 \mathrm{H}, 2.11 \text { (ddt, } J=14.0,7.4,6.8 \\
\text { Hz), } 2.11 \text { (dddd, } J=14.0,7.5,2.2,1.7 \mathrm{~Hz})), 3.26-3.55 \\
(2 \mathrm{H}, 3.34 \text { (ddd, } J=14.0,7.4,2.2 \mathrm{~Hz}), 3.47 \text { (ddd, } J=14.0, \\
7.5,6.7 \mathrm{~Hz})), 4.68-4.85(2 \mathrm{H}, 4.75(\mathrm{~d}, J=14.0 \mathrm{~Hz}), 4.78 \\
(\mathrm{d}, J=14.0 \mathrm{~Hz})), 4.98(1 \mathrm{H}, \mathrm{dd}, J=6.8,1.7 \mathrm{~Hz}), 6.87(1 \mathrm{H}, \\
\text { ddd, } J=7.9,7.5,1.3 \mathrm{~Hz}), 7.07-7.31(3 \mathrm{H}, 7.13(\mathrm{ddd}, J= \\
8.2,1.3,0.6 \mathrm{~Hz}), 7.24(\mathrm{ddd}, J=8.2,7.5,1.3 \mathrm{~Hz}), 7.24 \\
\text { (ddd, } J=7.9,1.3,0.6 \mathrm{~Hz})) .\end{array}$ \\
\hline
\end{tabular}

Time-kill kinetic antimycobacterial activity assay reveals synergy of the isolated fractions with INH on nutrient-starved M. smegmatis and M. bovis (BCG).

Nutrient starved $M$. smegmatis and $M$. bovis (BCG) showed enhanced growth than the normal replicating bacteria when inoculated in $7 \mathrm{H} 9$ media after starvation. The nutrient-starved $M$. smegmatis and $M$. bovis (BCG) exhibited a shorter lag phase than the non-nutrient starved one. In the case of nutrient-starved $M$. bovis (BCG), we also observed biofilm formation upon a more extended incubation period. Both nutrientstarved bacilli developed resistance against INH. For normal M. smegmatis, percentage inhibition upon INH treatment was observed to be $(38.70 \pm 0.023)$, the growth inhibition for nutrient-starved $M$. smegmatis was significantly decreased to (3.45 \pm 0.009$)$. Similarly, for nutrient-starved BCG, the percentage growth inhibition in the presence of $\mathrm{INH}$ was recorded $(6.50 \pm 0.004)$, which was significantly lower than that of the normal one (31.65 \pm 0.016$)$. (Figure 1)

The isolated alkaloid fractions obtained from $J$. adhatoda plant leaves showed significant growth inhibition on nutrient-starved $M$. smegmatis and $M$. bovis (BCG). The fractions significantly increased the lag phase and decreased the log phase of the bacterial growth curve. In the standard growth curve of nutrient-starved M. smegmatis, the lag phase was observed for 6 hours, followed by the log phase, which continued beyond Day 2, subsequently transforming to the stationary phase. While, most of the fractions decrease the log phase to Day 1 , making it less steep with time progress. Maximum inhibition was observed in $5 \mathrm{~A}$, followed by $5 \mathrm{~B}$, Vasicine, $2 \mathrm{~A}$, and $2 \mathrm{~B}$. 3A and 3B showed lower inhibition but the maximum synergy with $\mathrm{INH}$. The bacterial CFU reached $>10^{11} \mathrm{CFU} / \mathrm{mL}$ for the assay at Day 2 , from initial inoculum $1.5 \times 10^{6} \mathrm{CFU} / \mathrm{mL}$. While total CFU counted for the bacteria treated with the fractions was significantly lower than the control, indicating the bactericidal activity of the fractions on the bacteria. $2 \mathrm{~A}, 5 \mathrm{~B}$, and Vasicine showed bactericidal activity as $\log _{10}$ CFU decreased to $4-5$ for these fractions, even without INH. Whereas $3 \mathrm{~A}, 3 \mathrm{~B}$, and $5 \mathrm{~A}$ showed bacteriostatic effect having $\log _{10} \mathrm{CFU}$ more than 6 , i.e., $>10^{6} \mathrm{CFU} / \mathrm{mL}$. 
However, they exhibited bactericidal activity when incubated with $I N H$, as $\log _{10}$ CFU was reduced to $3\left(10^{3}\right.$ $\mathrm{CFU} / \mathrm{mL}$ ). The cumulative effect of the fractions and INH showed synergy in $3 \mathrm{~A}, 3 \mathrm{~B}, 5 \mathrm{~A}$, and $2 \mathrm{~B}$, where $3 \mathrm{~A}$ showed the best synergy and additive effect for Vasicine, 2A, and 5B. (Figure 2) For M. bovis (BCG), the lag phase was observed till Day 2, followed by the log phase from Day 2 to Day 7 . The stationary phase started from Day 8 to Day 28, with little growth from Day 21. In M. bovis (BCG), the maximum growth inhibition was observed on Day 7, followed by Day 21, and total CFU was counted on Day 7. For BCG, the fractions showed the bactericidal property in general, except $3 \mathrm{~A}$ and 3B. 5A and 5B showed the highest antimycobacterial activity, followed by Vasicine. Co-administration of the fractions with INH greatly enhanced the bactericidal property of the fractions. $3 \mathrm{~A}$ and $3 \mathrm{~B}$ showed bacteriostatic effect but exhibited bactericidal activity in the presence of INH. An additive effect was observed in the case of Vasicine, while 2A and 2B show no synergy with INH. Other fractions exhibited synergy with $\mathrm{INH}$, with fraction 3A showing the best synergy. (Figure 3 )

\section{Antimycobacterial activity of the fractions on BCG infected THP1 macrophages}

Annexin V dead cell apoptosis assay revealed that the isolated fractions targeted the BCG-infected macrophages when added at $\mathrm{IC}_{50}$ concentration, leading to cell death via apoptosis and necrosis. There was an increase in the percentage of cell death with the increase in incubation time, i.e., the rate of cell death was observed higher after $48 \mathrm{~h}$ incubation than $24 \mathrm{~h}$ incubation (Figure 4). Vasicine was ineffective on macrophages having internalized BCG, showing negligible cell death at $24 \mathrm{~h}$, while $\sim 20 \%$ death at $48 \mathrm{~h}$ (Figure 4, G). Fractions 2A, 3A, and 5A showed insignificant death at 24h incubation, which increased approximately $40 \%$ at $48 \mathrm{~h}$. Fraction $3 \mathrm{~B}$ showed $\sim 40 \%$ cell death at $24 \mathrm{~h}$ incubation, which reached $100 \%$ at 48h. A similar trend was observed for fraction $2 \mathrm{~B}$, exhibiting $40 \%$ death at $24 \mathrm{~h}$, while $\sim 80 \%$ cell death at $48 \mathrm{~h}$

incubation. Effect of time was not observed in the case of $5 B$, as percentage cell death $(\sim 20 \%)$ remained the same at $24 \mathrm{~h}$ and $48 \mathrm{~h}$.

Synergy was observed in the case of fractions $3 A, 3 B, 5 A$, and 5B against BCG-infected macrophages when treated along with $I N H$, where fractions $5 \mathrm{~A}$ and $5 \mathrm{~B}$ showed the best synergy. The antimycobacterial activity of these fractions increased more than $60 \%$ when treated with INH. Fraction $2 \mathrm{~A}$ and $2 \mathrm{~B}$ showed additive effects with INH on BCG-infected macrophages with a 30\% increase in antimycobacterial activity. In the case of Vasicine, there was no impact of INH, as no increase in the cell death of BCG-infected macrophages. While most of the fractions showed late apoptosis, 3A and 3B caused cell death due to necrosis. (Figure $4 \& 5)$

\section{THP1 macrophages showed colocalization of M. bovis (BCG) and Lysosomes when treated with the isolated fractions.}

Mycobacterium bacilli, i.e., M. bovis (BCG) and M. tuberculosis, can prevent the host cell from forming lysosomes, making it their temporary resident. Upon treatment with the isolated fractions, the BCG-infected THP1 macrophage cells produce lysosomes targeted explicitly towards the bacilli. GFP-tagged BCG and Lysotracker Red-stained LAMP-1 protein, expressed on the lysosomes, were colocalized and analyzed by using the software. Yellow coloration indicates colocalization, obtained due to the superimposition of red 
and green colors. Percent colocalization, measured by the software, was recorded highest in 2A, 2B, and 5B. $5 \mathrm{~A}$ and Vasicine showed moderate, while no colocalization was found for $3 \mathrm{~A}, 3 \mathrm{~B}$, and INH. For the fractions showing significant colocalization, the percent green overlap was significantly higher than the red overlap, except $5 \mathrm{~A}$ and $5 \mathrm{~B}$.

The above result implies that other fractions promote lysosome production spread across the cytoplasm, while $5 \mathrm{~A}$ and $5 \mathrm{~B}$ direct lysosomes towards the internalized bacteria. In Vasicine and 2B, profound lysosome production was noted. (Figure 6) Macrophages expressed a significantly higher number of lysosomes directed towards the ingested bacilli when co-administered with the fractions and INH. All fractions except $3 \mathrm{~A}$ showed an increase in the percent colocalization when co-administered with $\mathrm{INH}$. Fractions $2 \mathrm{~B}$ and $5 \mathrm{~B}$ showed synergy with INH, while VAS, 2A, 3B, and 5A showed additive effect with INH for phagolysosome fusion. (Figure 7) The above result shows that the alkaloid fractions isolated from J. adhatoda leaf help macrophages kill internalized BCG by promoting phagolysosome fusion.

\section{Discussion}

Plants are the inexhaustible resource of natural products used as folk medicines since humanity. Although the popularity of synthetic drugs increased due to their cost effectiveness, easy quality control, and immediate effects, the rise of resistant bacterial strains and severe side effects makes their use questionable. A vast number of natural product-derived compounds in the pipeline highlights the significance of plants as sources of new drug candidates. ${ }^{8,9,23}$

Justicia adhatoda, a well-known indigenous Indian subcontinental plant, is commonly used to treat respiratory ailments in folk medicine. Our study explored the antimycobacterial potential of the plant leaf extracts and successfully isolated and characterized bioactive compounds, besides Vasicine, responsible for the activity. The isolated fractions, labeled as 2A, 2B, 3A, 3B, 5A, and 5B, were identified as alkaloids, constituting Vasicoline, Vasicolinone, Adhatodine, Adhavasine, Aniflorine, and Vasicinone, respectively. Our previous study proved that the compounds showed excellent antimycobacterial activity against $M$. smegmatis and $M$. bovis, better than the first-line drugs Isoniazid (INH) ${ }^{22}$ The fractions also showed synergy against both bacilli with $\mathrm{INH}$. The present study analyzed the potential antimycobacterial activity of the isolated fractions on nutrient-starved $M$. smegmatis and $M$. bovis (BCG). We found that the fractions inhibit bacterial growth and possess a profound bactericidal effect when co-administered with INH. As the nutrient-starved bacilli act as a Latent TB model, the results are a significant milestone for further research for anti-TB drug development. The activity of Aniflorine, Vasicoline, and Vasicolinone was exceptional, as these compounds not only showed profound antimycobacterial inhibition on the nutrient-starved $M$. smegmatis and $M$. bovis (BCG) but also showed synergy with INH. Although Adhatodine and Adhavasine exhibited lower antimycobacterial activity than the other compounds, they showed maximum synergy with $\mathrm{INH}$.

Dead cell apoptosis assay, performed on BCG-infected THP1 macrophages in the presence of the isolated compounds, gave more insight. The compounds were efficacious on the intracellular BCG, causing infected macrophages' death and showing synergy with $\mathrm{INH}$. When co-administered with $\mathrm{INH}$, compounds caused 
cell death due to apoptosis, while Adhatodine and Adhavasine showed necrosis even with INH. Although Vasicine showed excellent antimycobacterial activity on $M$. smegmatis and $M$. bovis (BCG), it was ineffective on intracellular BCG. The efficacy of Vasicine remains unchanged even in the presence of INH. Mycobacterium tuberculosis is well known for its adaptability and quick resistant development. A significant paradigm in TB pathogenesis is that the internalized bacteria use the host cell mechanism to inhibit phagosome-lysosome fusion, making the condition favorable for latency. The extant drugs cannot target the internalized TB bacilli, which targets host cells, thus causing severe side effects. Our preliminary results suggest that the compounds isolated from J. adhatoda leaf promote phagosome-lysosome fusion. The lysosomes were directed towards the internalized bacilli. The combined effect of the compounds and $\mathrm{INH}$ showed an increase in phagolysosome fusion. However, Vasicine and Adhavasine showed no change in percentage colocalization of internalized BCG and lysosomes, even when administered with $\mathrm{INH}$.

Vasicine is a well-known bronchodilator used for cough treatment. Several in-silico studies and a few invitro studies show its antimicrobial, antioxidant, and cytotoxic potential. ${ }^{24,25}$ Vasicine is also known as a moderate anti-tubercular agent. ${ }^{26}$ Some in-silico studies on the derivatives of Vasicine, such as Vasicinone, Vasicoline, and Vasicolinone, suggest the anti-TB activity along with anti-proliferative and hepatoprotective effects, where the activity of Adhatodine, Adhavasine, and Aniflorine has not yet been assigned. 27,28

Our study is one of its first kind, where we assessed the in-vitro antimycobacterial activity of these derivatives on nutrient-starved $M$. smegmatis and $M$. bovis (BCG). We support our findings with the study conducted on BCG-infected macrophages. The compounds showed effective in-vitro antimycobacterial activity on both bacilli and showed synergy with the first-line drug INH. The alkaloids also showed antiproliferative activity on BCG-infected macrophages and proved more effective than INH and Vasicine. They also promote phagolysosome fusion which shows their effect targeted towards the internalized bacilli. Aniflorine, Vasicoline, Vasicolinone, and Vasicinone showed excellent in-vitro antimycobacterial effects and good anti-proliferative activity. They also showed phagosome-lysosome fusion, better than the other compounds. Vasicoline and Vasicolinone showed additive effects, while Aniflorine and Vasicinone showed synergy with INH. Although Vasicine shows excellent in-vitro antimycobacterial activity, its impact on internalized $M$. bovis (BCG) was poor. Neither it showed the anti-proliferative effect nor showed phagolysosome fusion in BCG-infected THP1 macrophages. However, Vasicine showed synergy with INH for phagolysosome fusion.

Our study proves that $J$. adhatoda is rich in bioactive compounds responsible for the anti-tubercular activity, which should be pursued further for anti-TB drug development. The study also directs the in-vitro and exvivo antimycobacterial potential of quinazoline alkaloids in $\mathrm{J}$. adhatoda and suggests their effectiveness more than vasicine, the principal alkaloid in the plant. The compounds need to be analyzed further on $M$. tuberculosis and also on the animal model. In-silico and in-vitro study of the isolated compounds, especially Aniflorine, Adhavasine, and Adhatodine, should be conducted in perspective of phagosome-lysosome fusion in M. tuberculosis internalized in macrophages to understand the mechanism of action of the compounds.

\section{Methods}




\section{Bacterial samples, cell lines, and chemical procurement}

Bacterial samples viz.- Mycobacterium smegmatis strain $\mathrm{mc}^{2} 155$ and Mycobacterium bovis (BCG-Pasteur) were procured from the Department of Pathology, AlIMS, and Department of Biomedical Sciences, University of Delhi, North Campus, respectively. Procurement of GFP tagged Mycobacterium bovis (BCG) and THP1 cell lines from Department of Biomedical Sciences, University of Delhi, North Campus. Middlebrook 7H9 and 7H11, Oleic acid Albumin Dextrose Catalase (OADC), and Albumin Dextrose Catalase (ADC) supplements were purchased to maintain the bacterial cultures from Himedia.

For animal cell line propagation- Rosewell Park Memorial Institute 1640 (RPMI1640), Foetal Bovine Serum (FBS), 0.25\% Trypsin-EDTA solution, Pen-Strep solution (10,000U/mL), 96 well microtiter plates, serological pipettes, and $T_{25}$ and $T_{75}$ Flasks (Gibco and Nunc) were used. THP1 differentiation into macrophages, cell stimulation cocktail containing phorbol 12-myristate 13-acetate (PMA) and ionomycin, Dead cell apoptosis kit, Lysotracker Red, and 4',6-diamidino-2-phenylindole (DAPI) were purchased from Thermo Fisher. Solvents (both analytical and HPLC grade) were purchased from SRL chemicals and Merck. Deuterated Chloroform for NMR analysis, tyloxapol, and Isoniazid (INH) were purchased from Sigma Aldrich.

\section{Declaration Statement}

Justicia adhatoda L. plant leaves were acquired from Kamala Nehru Ridge, New Delhi, located on the University of Delhi campus, provided by the garden officer of the University of Delhi. The plant material was procured legally, under the national guidelines and legislation of the National Biological Diversity Act, 2002, formulated by the Central Government vide notification S.0.1911(E) of the Government of India. ${ }^{29}$ Submission of the plant for sample verification and authentication was made at NISCAIR, PUSA Road, Delhi. The sample authentication number - NISCAIR/RHMD/Consult/ 2015/2907/100. The herbarium was also created and deposited in the Department of Botany, University of Delhi. All experiments were performed by following the standard protocols approved by WHO biological reference standards. ${ }^{30}$

\section{Plant Material Collection, Extract Preparation, And Alkaloid Isolation}

Plant leaves, acquired in October from Kamala Nehru Ridge, New Delhi, were washed, shade dried, and powdered. The methanol extract was prepared by dissolving powdered leaves in methanol (1:10 leaf: solvent ratio). The mixtures were stirred overnight on the magnetic stirrer at room temperature. The solution was filtered after 72 hours of incubation and concentrated by a rotary evaporator. Alkaloids were isolated via the acid-base extraction method by treating the extract with an excess of $1 \%$ citric acid solution. The mixture was stirred overnight, filtered, and suspended in chloroform. The aqueous and chloroform layer was separated and concentrated. The aqueous layer was basified to $\mathrm{pH} 9.5$ using $\mathrm{NH}_{4} \mathrm{OH}$ and further extracted using chloroform and treated with $\mathrm{Na}_{2} \mathrm{SO}_{4}$ (in excess), filtered, and again concentrated. The obtained compound mixture was measured with Acetone and Petroleum ether (1:1 ratio; 40ml each) and filtered to 
get purified alkaloid - Vasicine. The qualitative tests for the first fraction confirmed the identity as an alkaloid.

\section{Alkaloid Fractionation And Isolation}

The alkaloid fraction obtained was subjected to TLC analysis to standardize the mobile phase for further fractionation. After standardization, Prep TLC was performed using $45 \%$ ethyl acetate, $35 \%$ methanol, and $20 \%$ chloroform as mobile phase at $\mathrm{pH} 9.5$ adjusted by adding $\mathrm{NH}_{4} \mathrm{OH}$. Different bands were obtained and re-fractionated to varying polarities of the mobile phase adjusted accordingly. Fractions were subjected to antimycobacterial activity assay, and out of several, the best fractions were selected for further analysis. (Antimycobacterial activity data has been published)

\section{Compound Characterization}

HPLC analysis: Isolated fractions were first subjected to HPLC analysis, C18 column, 95\% Methanol; $4 \%$ Acetonitrile; $1 \%$ Tetrahydrofuran as mobile phase isocratic solvent. The injection volume was $20 \mu \mathrm{l}$, and the running time was 20 minutes. Mass Spectrometry: $5 \mathrm{mg}$ of the isolated fractions were submitted to the QTof HRMS facility of SAIF CDRI Lucknow for analysis. NMR analysis: Isolated compounds were subjected to $\mathrm{H}^{+} \mathrm{NMR}$ analysis. $7-8 \mathrm{mg} / \mathrm{ml}$ of the samples were dissolved in $500 \mu \mathrm{l}$ of Deuterated Chloroform and subjected for NMR analysis at USIC, North Campus, University of Delhi. FTIR spectrometry: To determine the functional groups present, $5 \mathrm{mg}$ of the samples were dissolved in methanol (HPLC grade solvent) and submitted for FTIR analysis to AIRF, JNU.

Preparation of nutrient-starved M. smegmatis and M. bovis (BCG)

The nutrient starvation model is designed by following the method standardized by Loebel et al. ${ }^{31}$ Stocks of bacterial culture obtained were revived in 7H9 broth containing 10\% OADC/ADC supplement. The $M$. smegmatis and $M$. bovis (BCG) cultures were incubated at $37^{\circ} \mathrm{C}$ for 24 hours and seven days. Afterward, the cultures were streaked on a $7 \mathrm{H} 11$ agar plate (containing $10 \%$ ADC and OADC growth supplement for $M$. smegmatis and $\mathrm{BCG}$ ), and colonies were obtained after 3-5 days and 21 days for $M$. smegmatis and BCG, respectively. Cultures of $M$. smegmatis $\mathrm{mc}^{2} 155$ and $M$. bovis (BCG) were grown till the log phase reached (24 hours for $M$. smegmatis, where the OD of culture, taken at $600 \mathrm{~nm}$, was observed to be 0.6 and 7 days for M. bovis where the OD of culture, taken at $600 \mathrm{~nm}$, was honored to be 0.48.) in Middlebrook 7H9 media supplemented with $10 \%$ OADC (for M. bovis) or ADC (for $M$. smegmatis) and $1 \%$ glycerol. Both cultures were centrifuged at $3000 \mathrm{rpm}$ for 5 minutes. Media was discarded, and culture pellets were washed out three times with $1 \mathrm{X}$ PBS. The bacterial cultures were incubated at $37^{\circ} \mathrm{C}$ in PBS solution supplemented with Tyloxapol for single-cell suspension (non-degradable detergent). The incubation period for $M$. smegmatis was 15 days, whereas for $M$. bovis, its 4-6 weeks long. As nutrients were not provided, the OD of both cultures remained the same after the incubation period. After the completion of the incubation period, cultures were centrifuged at $3000 \mathrm{rpm}$ for 5 minutes and resuspended in fresh $7 \mathrm{H} 9$ media supplemented 
with $10 \%$ OADC/ADC and $0.5 \%$ glycerol. OD of the cultures was standardized at $0.1(M$. smegmatis) and $0.3(M$. bovis $)$ for further experimentation.

Antimycobacterial activity assay and synergy with INH on nutrient-starved M. smegmatis and $\mathrm{M}$. bovis (BCG) in a time-kill kinetic manner

Cultures of $M$. smegmatis and $M$. bovis (BCG) $\left(10^{6} \mathrm{CFU} / \mathrm{ml}\right)$ were incubated with the isolated fractions at their $\mathrm{IC}_{50}$ concentration determined previously (Data has been published). Another set containing the isolated fractions with the first-line drug INH was incubated with bacterial cultures $\left(10^{6} \mathrm{CFU} / \mathrm{ml}\right)$. The culture tubes were incubated at $37^{\circ} \mathrm{C}$ in an incubator shaker. Before the incubation, $500 \mu \mathrm{l}$ of the milieu was taken out, and absorbance was recorded at $600 \mathrm{~nm}$ as 0 hour reading. For M. smegmatis, the absorbance of the treated cultures was recorded at $1,2, \ldots 8,24$ hours, till day 7 . For $M$. bovis (BCG), the readings were taken at $4,8,24$ hours, till day 28 . Positive and negative controls were maintained to negate the errors. The graph between absorbance at $600 \mathrm{~nm}$ and time was plotted to obtain the bacterial growth curve. The treated bacterial culture was centrifuged, washed by PBS, and suspended in fresh uninoculated 7H9 broth at the maximum inhibition. Dilutions were made for the suspended bacterial culture, spread on the $7 \mathrm{H} 11$ plates, and determined bacterial CFU.

\section{Intracellular Antimycobacterial Assay Dead cell apoptosis assay}

THP-1 cell lines were maintained in RPMI 1640 with 10\% FBS in the presence of Pen-strep solution. THP1 cells were transferred to 12 well plates $\left(10^{6}\right.$ cells per well) and stimulated to Macrophages using a Cell stimulation cocktail. The cell lines were left overnight, washed with 1XPBS, and replenished with RPMI 1640 media. Newly differentiated THP1 cells into macrophages were then infected with M. bovis (BCG), cultivated in $7 \mathrm{H} 9$ broth containing $10 \% \mathrm{OADC}$ and $1 \%$ Glycerol. Bacterial culture was grown till log phase $\left(0.6 \mathrm{OD}_{600}\right)$ and then diluted to get $7.5 \mathrm{Mol}$ (Multiplicity of Infection). The infected macrophages were treated with the isolated fractions at their $\mathrm{IC}_{50}$ concentration for 24 hours and 48 hours. Incubated cells were then harvested and washed with 1XPBS twice and pelleted out. Using Annexin V dead cell apoptosis kit by Thermo Fisher, the cells were treated with Annexin $\mathrm{V}$ binding buffer and subsequently tagged with Fluorescein isothiocyanate (FITC) and Propidium lodide (PI) as per the instruction manual. The cells were subjected to FACS analysis.

Co-localization of M. bovis (BCG) and Lysosomes in THP1 Macrophage infected.

In 12 well plates, sterile coverslips were inserted, and $1 \mathrm{ml}$ RPMI 1640 media was added to each well. Wells were seeded with THP1 cells $\left(10^{6}\right.$ cells per well) and treated with a cell stimulation cocktail at $1 \mu \mathrm{g} / \mathrm{ml}$ concentration to induce THP1 differentiation into macrophages. Treated cells were left for overnight incubation at $37^{\circ} \mathrm{C}$. The media was removed, cells were washed gently with RPMI 1640 media after incubation, and fresh media was added for further use. On the other hand, GFP tagged M. bovis (BCG) 
colony was cultured on $7 \mathrm{H} 11$ agar plates, containing 10\% OADC and 1\% Glycerol. Hygromycin was used to select the GFP-expressing colonies. The bacterial colony was grown in 7H9 broth under optimum temperature with $10 \%$ OADC and $1 \%$ Glycerol as growth supplement till log phase $\left(0.6 \mathrm{OD}_{600}\right)$ and then diluted to get $7.5 \mathrm{Mol}$ (Multiplicity of Infection). The cells were treated with isolated fractions at their $\mathrm{IC}_{50}$ concentration, and GFP tagged BCG were added and incubated for 3 hours. After incubation completion, media was discarded, and cells were gently washed. Cells were then treated with Lysotracker Red $(1 \mathrm{ng} / \mathrm{ml})$ for 1 hour and washed twice with PBS. Slides were prepared by putting the coverslips from the wells on the slide containing a drop of DAPI stain. Slides were observed under a confocal microscope at specific wavelengths and analyzed with the help of Just Another Colocalization Plugin (JACoP) plugin in ImageJ software.

\section{Statistical analysis}

Graphpad Prism 5.0 was used to plot graphs and calculate p-value by performing a t-test for time-kill kinetic assay on nutrient-starved Mycobacterium. All Experiments were performed at least thrice, and results are represented as Mean and Standard Deviation (SD). Negative and positive controls were taken into consideration in all assays performed. INH was used as a standard anti-TB drug for comparison. Grammar and plagiarism have been checked using the software Grammarly Premium. FACS images were analyzed by using offline software Cyflgoic for calculating percentage apoptosis and necrosis. Co-localization in confocal images, Pearson's coefficient, and percentage overlap was calculated with the help of offline software ImageJ plugin JACoP.

\section{Declarations}

\section{Acknowledgment}

The authors are thankful to Shaheed Rajguru College of Applied Sciences, University of Delhi, for providing the research facility to conduct the study. The authors are also grateful to the CSIR-Central Drug Research Institute for HRMS and FTIR analysis of the fractions.

\section{References}

1. Singh, A. R. \& Modern Medicine Towards Prevention, Cure, Well-being and Longevity. Mens Sana Monographs, 8, 17 (2010).

2. Why modern medicine is a major threat to public health | Aseem Malhotra | The Guardian. https://www.theguardian.com/society/2018/aug/30/modern-medicine-major-threat-public-health

3. GLOBAL TUBERCULOSIS REPORT 2020. (2020)

4. Huddart, S., Svadzian, A. \& Nafade, V. Tuberculosis case fatality in India: a systematic review and metaanalysis.BMJ Glob Health5, (2020)

5. Tiberi, S. et al. New drugs and perspectives for new anti-tuberculosis regimens. Revista Portuguesa de Pneumologia (English Edition), 24, 86-98 (2018). 
6. Fogel, N. \& Tuberculosis A disease without boundaries. Tuberculosis, 95, 527-531 (2015).

7. Sagar Pramod, P. \& Nomina Vishnu, A. Asian Journal of Pharmaceutical Science \& Technology A REVIEW ON SAFETY OF AYURVEDIC MEDICINE. 2, 2012-88

8. Pan, S. Y. et al. Historical perspective of traditional indigenous medical practices: The current renaissance and conservation of herbal resources. Evidence-based Complementary and Alternative Medicine 2014, (2014)

9. Salim, A., Chin, Y. \& Kinghorn, A. Drug Discovery from Plants AA Bioactive Molecules and Medicinal Plants 1-25 (2008) doi:10.1007/978-3-540-74603-4

10. Arya, V. A. \& Review on Anti-Tubercular Plants. 3, 872-880 (2011)

11. Arora, P. Importance of Adhatoda Vasica Nees In Traditional System of Medicines: A Review.American Journal of PharmTech Research(2019)

12. Rachana, Sujata, B., Mamta, P., Priyanka, K. M., Sonam, S. \& Review Future Perspectives of Using Vasicine, and Related Compounds. Indo-Global Journal of Pharmaceutical Sciences, 1, 85-98 (2011).

13. Justicia adhatoda - an overview | ScienceDirect Topics. https://www.sciencedirect.com/topics/pharmacology-toxicology-and-pharmaceutical-science/justiciaadhatoda

14. Asia, W. H. Organization. R. O. for S.-E. The use of traditional medicine in primary health care. SEARO regional health papers; no. 19 xi, 143 (1990)

15. Medicine, C. L. Ethnobotanical uses of medicinal plant, Justicia adhatoda L. by Meitei community of Manipur, India. Journal of Coastal Life Medicine, 1-5, https://doi.org/doi:10.12980/jclm.1.2013c895. (2013).

16. Pa, R. \& Mathew, L. Antimicrobial activity of leaf extracts of Justicia adhatoda L. in comparison with vasicine. Asian Pacific Journal of Tropical Biomedicine, 2, S1556-S1560 (2012).

17. Dhankhar, S. et al. A review on Justicia adhatoda: A potential source of natural medicine. African Journal of Plant Science, 5, 620-627 (2011).

18. Dilip Chaudhari, S. \& Someshwar Jamdade, S. A complete over review on Adhatoda vasica a traditional medicinal plants. (2021)

19. Gheware, A. et al. Adhatoda Vasica attenuates inflammatory and hypoxic responses in preclinical mouse models: potential for repurposing in COVID-19-like conditions. Respiratory Research 2021 22:1 22, 1-15(2021)

20. Duraipandiyan, V. et al. Antimicrobial, antioxidant, and cytotoxic properties of Vasicine acetate synthesized from Vasicine isolated from adhatoda vasica I. BioMed Research International 2015, (2015)

21. Liu, W. et al. In Vitro and In Vivo Metabolism and Inhibitory Activities of Vasicine, a Potent Acetylcholinesterase and Butyrylcholinesterase Inhibitor. PLOS ONE, 10, e0122366 (2015).

22. Mishra, S., Khatri, M. \& Mehra, V. Assessing the antimycobacterial activity of the bioactive fractions of the Indian medicinal plant - Justicia adhatoda L. Chemical Biology Letters, 8, 67-78 (2021). 
23. Indian Herbal Drug for General Healthcare: An Overview. The Internet Journal of Alternative Medicine6, (2008)

24. Duraipandiyan, V. et al. Antimicrobial, antioxidant, and cytotoxic properties of Vasicine acetate synthesized from Vasicine isolated from adhatoda vasica I. BioMed Research International, 2015, 7-13 (2015).

25. Perumal Samy, R., Ignacimuthu, S. \& Sen, A. Screening of 34 Indian medicinal plants for antibacterial properties. Journal of Ethnopharmacology, 62, 173-181 (1998).

26. Ignacimuthu, S. \& Shanmugam, N. Antimycobacterial activity of two natural alkaloids, vasicine acetate and 2-acetyl benzylamine, isolated from Indian shrub Adhatoda vasica Ness. leaves. Journal of Biosciences 2010 35:4 35, 565-570 (2010)

27. Kumar Jain, C. Docking studies to investigate interactions of vasicine molecule with oxidative enzymes. Journal of Pharmacy Research, 4, 3907-3909 (2011).

28. Arora, P. Importance of Adhatoda Vasica Nees In Traditional System of Medicines: A Review.American Journal of PharmTech Research(2019)

29. National Biodiversity Authority - FAQ. http://nbaindia.org/content/19/16/1/faq.html

30. Annex 2 Recommendations for the preparation, characterization and establishment of international and other biological reference standards (revised 2004)

31. Patel, K., Jhamb, S. S. \& Singh, P. P. Models of Latent Tuberculosis: Their Salient Features, Limitations, and Development. Journal of Laboratory Physicians, 3, 75 (2011).

\section{Figures}



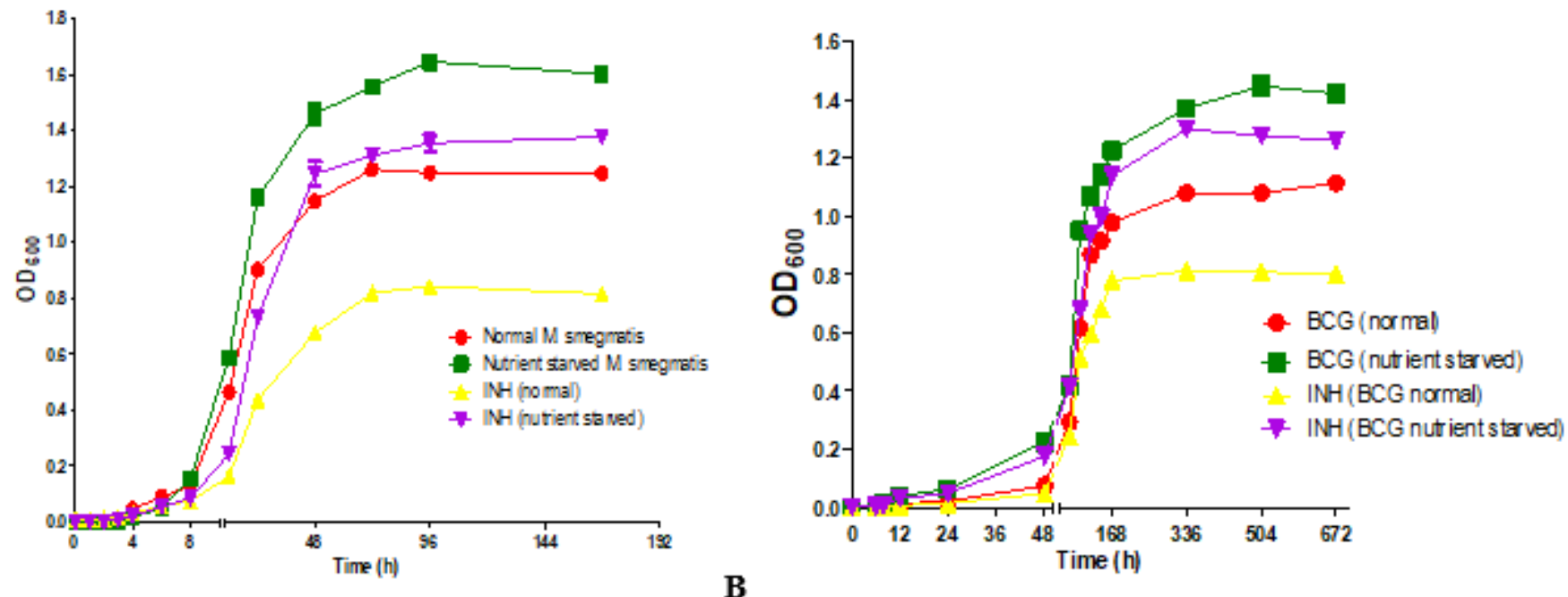

A

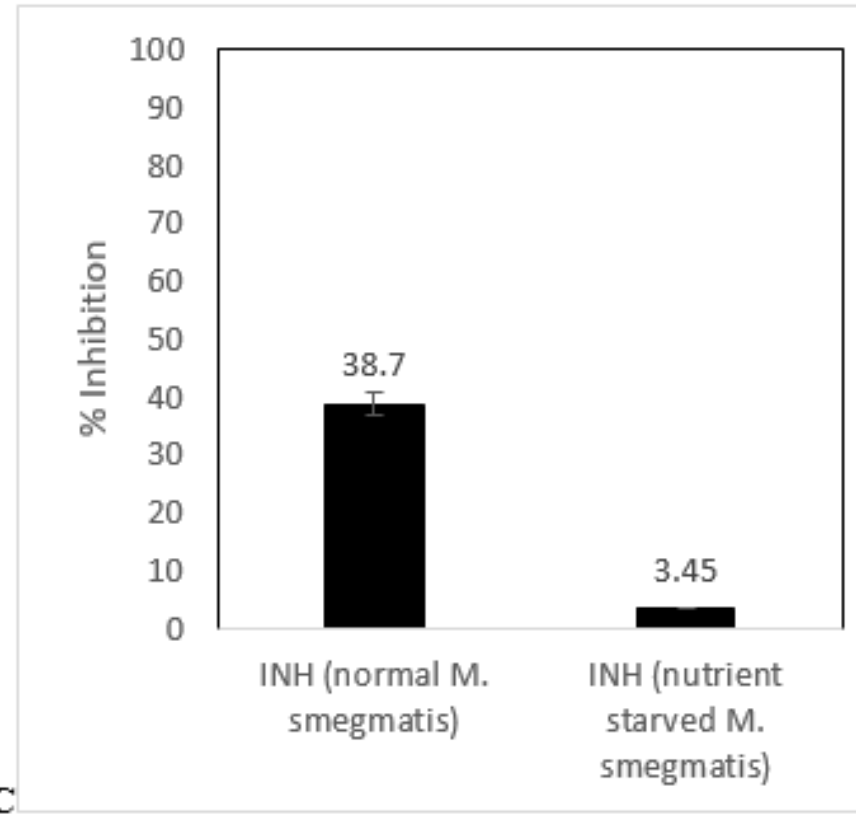

B

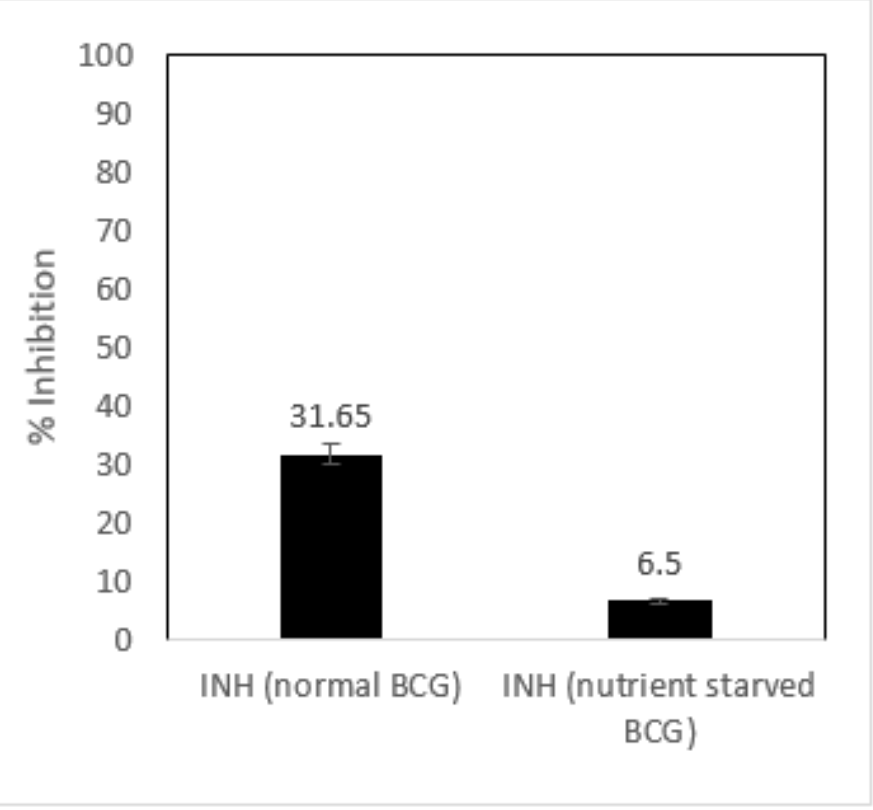

Figure 1

Comparison between normal and nutrient-starved bacterial growth for $(A) M$. smegmatis and (B) M. bovis (BCG) in the presence and absence of the first-line drug INH, by plotting the growth curve. Percentage inhibition by INH is shown in (C) for M. smegmatis at Day 2 and (D) for M. bovis (BCG) at Day 7. Values are plotted as Mean \pm SEM, $n=3$. 
A

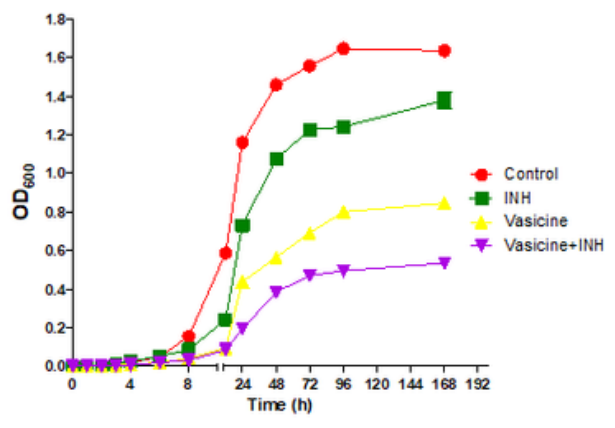

B

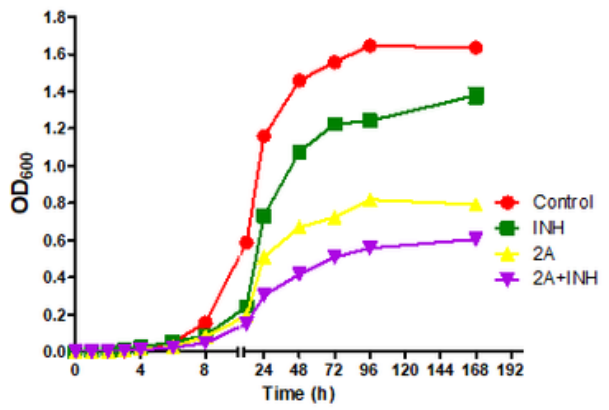

C

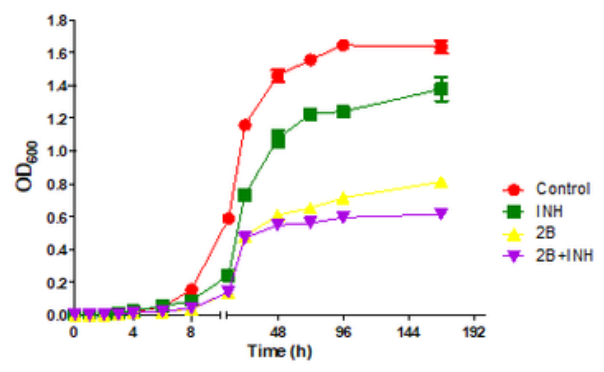

D
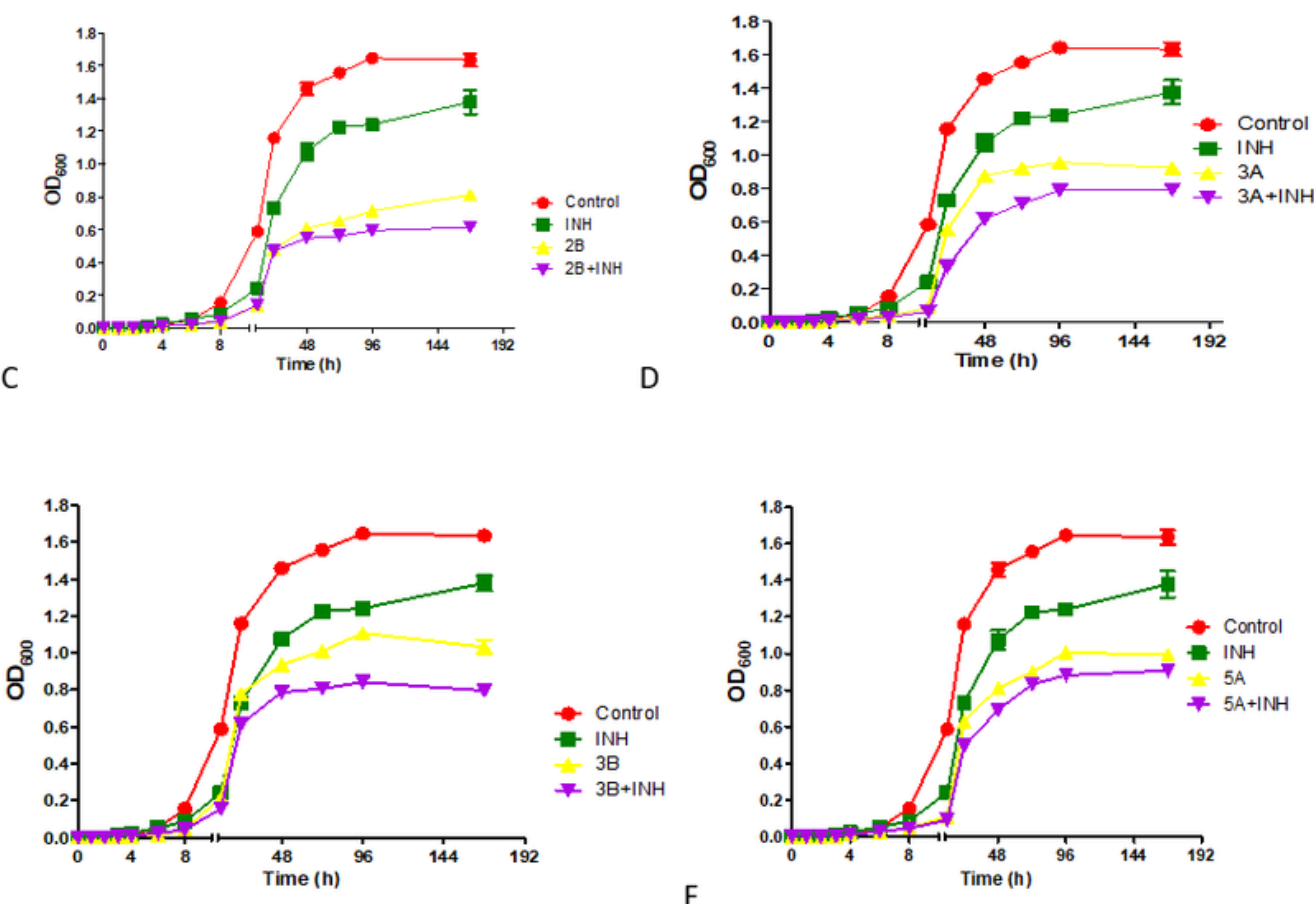

$\mathrm{F}$

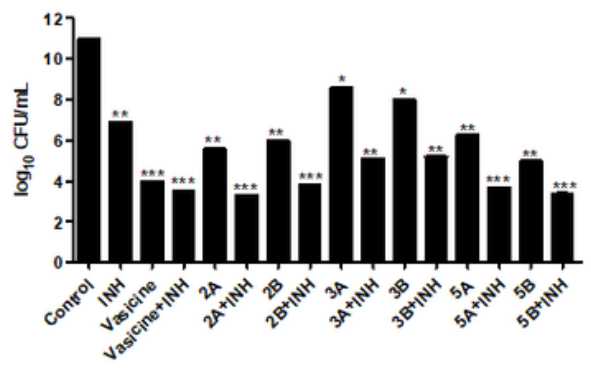

\section{Figure 2}

Graphical representation of time-kill kinetic assay on Nutrient starved M. smegmatis showing the change observed in the growth curve in the presence of $(A)$ Vasicine, $(B) 2 A,(C) 2 B,(D) 3 A,(E) 3 B$, (F) 5A, and (G) $5 B$, with and without INH. $(H)$ shows the bacterial CFU on Day 2 when treated with the isolated fractions with and without the co-treatment of INH to determine potential synergy. Values are plotted as Mean \pm SEM, $\mathrm{n}=3 .{ }^{*} \mathrm{p}$-value $<0.05,{ }^{* *} \mathrm{p}$-value $<0.001,{ }^{* *} \mathrm{p}$-value $<0.001$; t-test result compared to Control (bacterial growth without inhibitor) at Day 2. 
A

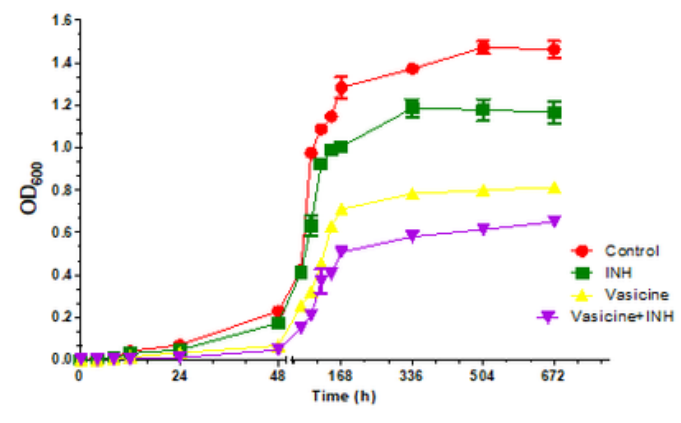

B

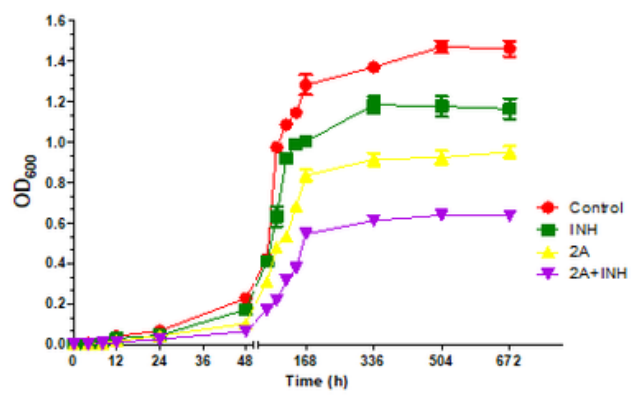

C
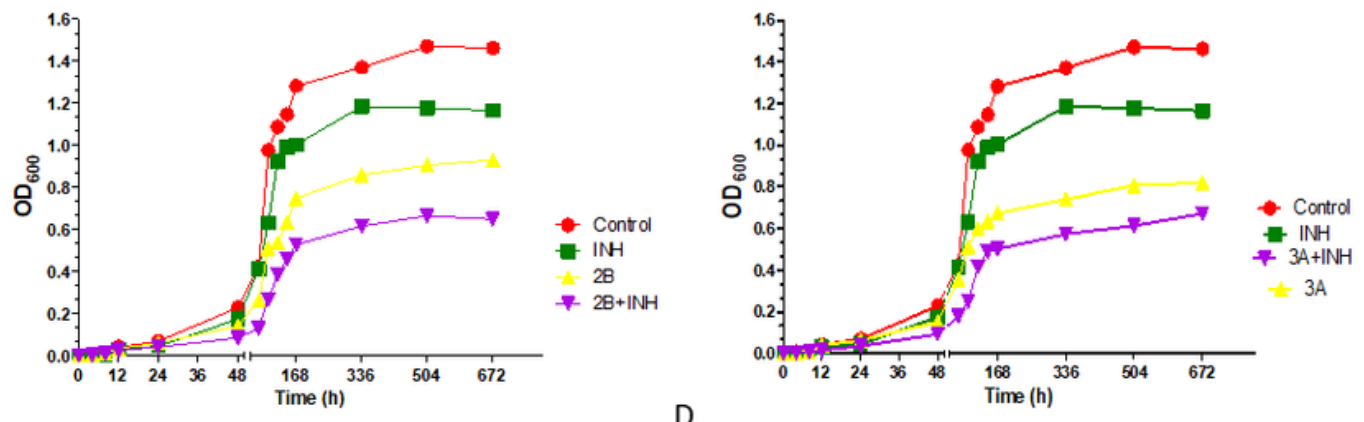

D
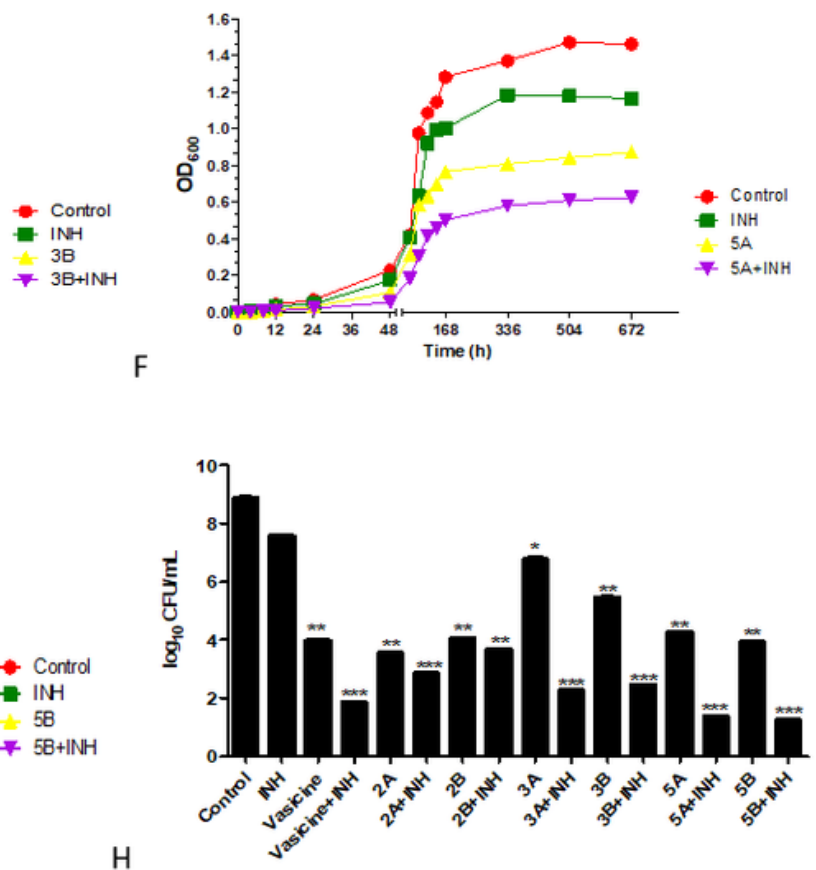

\section{Figure 3}

Graphical representation of time-kill kinetic assay on Nutrient starved M. bovis (BCG) showing the change observed in the growth curve in the presence of $(A)$ Vasicine, (B) 2A, (C) 2B, (D) 3A, (E) 3B, (F) 5A, and (G) $5 \mathrm{~B}$, with and without INH. $(\mathrm{H})$ shows the bacterial CFU on Day 2 when treated with the isolated fractions with and without the co-treatment of INH to determine potential synergy. Values are plotted as Mean \pm SEM, $\mathrm{n}=3 .{ }^{*} \mathrm{p}$-value $<0.05,{ }^{* *} \mathrm{p}$-value $<0.001,{ }^{* *} \mathrm{p}$-value $<0.001$; t-test result compared to Control (bacterial growth without inhibitor) at Day 7 . 
A

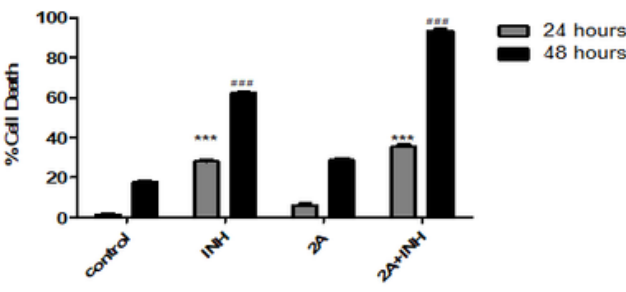

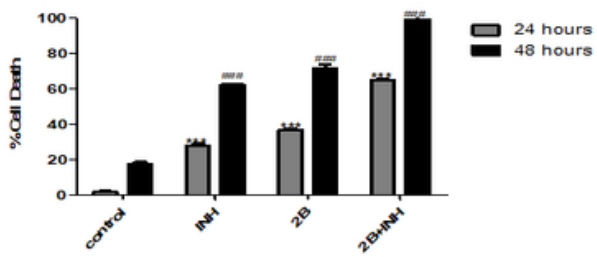

C
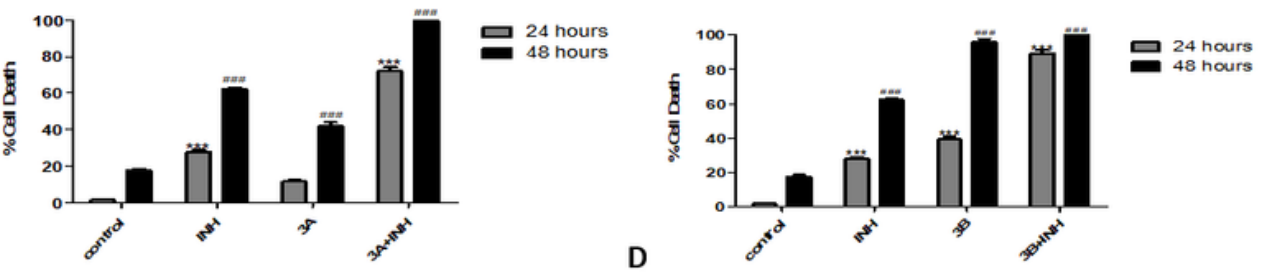

$\mathbf{E}$
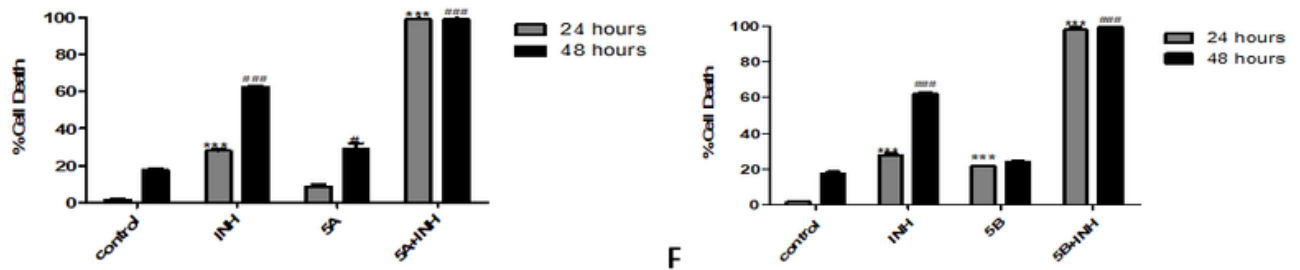

G
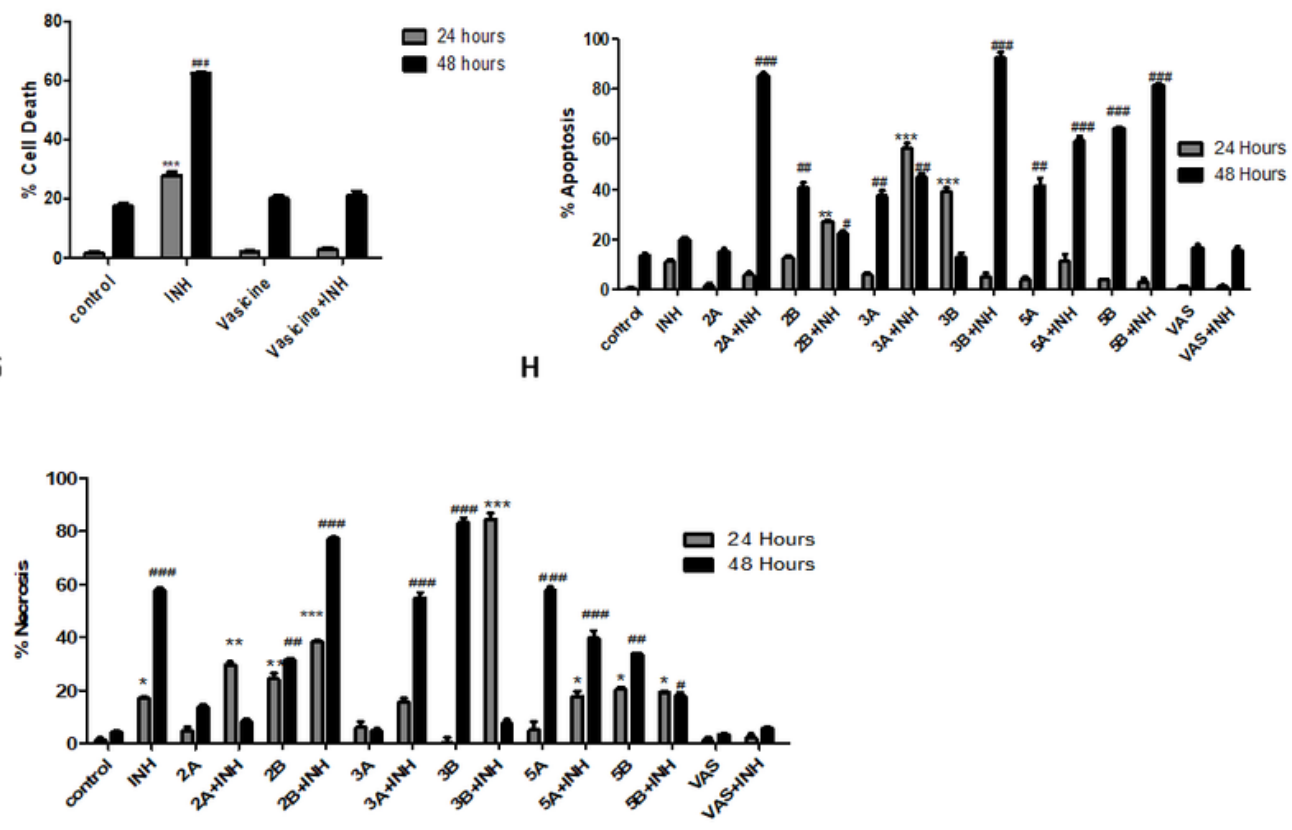

Figure 4

Description of \%Cell death of BCG infected macrophages upon treatment with (A) 2A, (B) 2B, (C) 3A, (D) 3B, (E) 5A, (F) 5B, and (G) Vasicine. Graphs (H) and (I) represented \%Apoptosis and \%Necrosis respectively, occurred upon treatment with isolated fractions for 24 and 48 hours. Values are plotted as Mean \pm SEM, $n=3$. ${ }^{*} p$ value $<0.05,{ }^{* \star} p$ value $<0.001,{ }^{* \star *} p$ value $<0.001$; t-test result compared to Control (bacterial growth without inhibitor) at 24 hours. \#p value $<0.05$, \#\#p value $<0.001$, \#\#\# p value $<0.001$; t-test result compared to Control (bacterial growth without inhibitor) at 48 hours. 


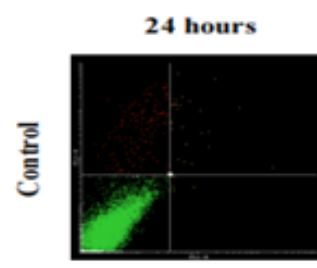

48 hours
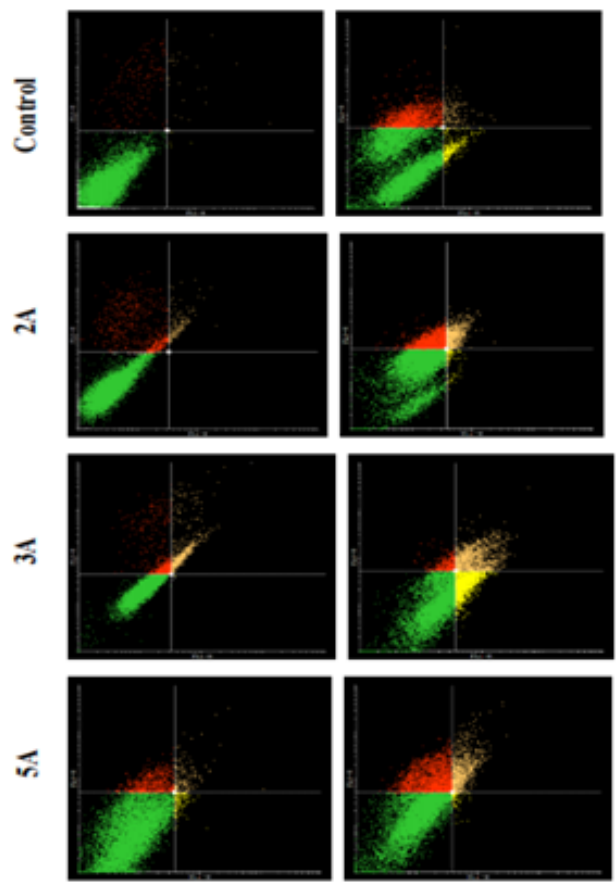

24 hours
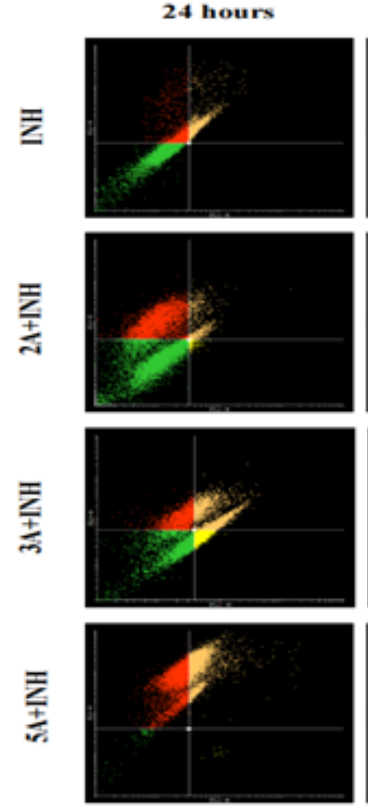

48 hours
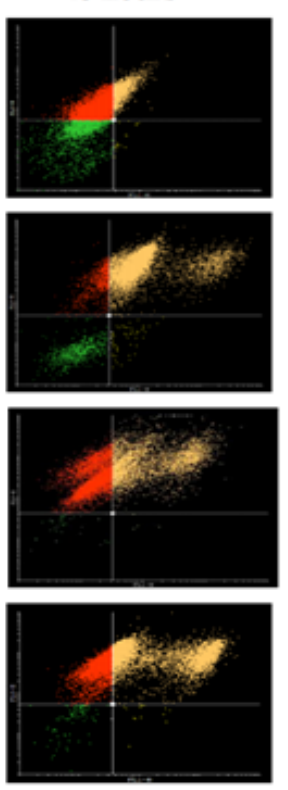
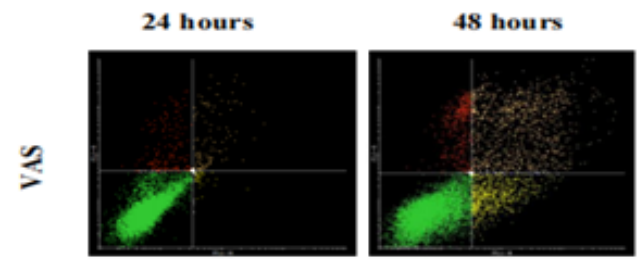

กี
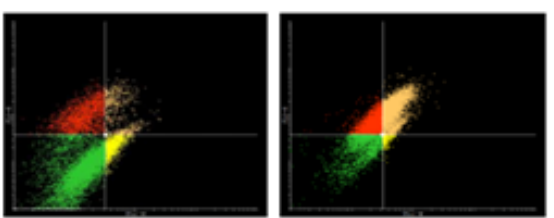

लै
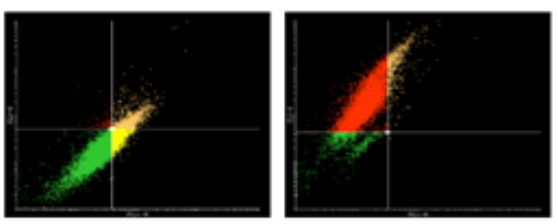

क
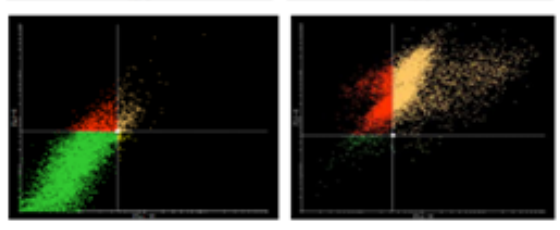

24 hours
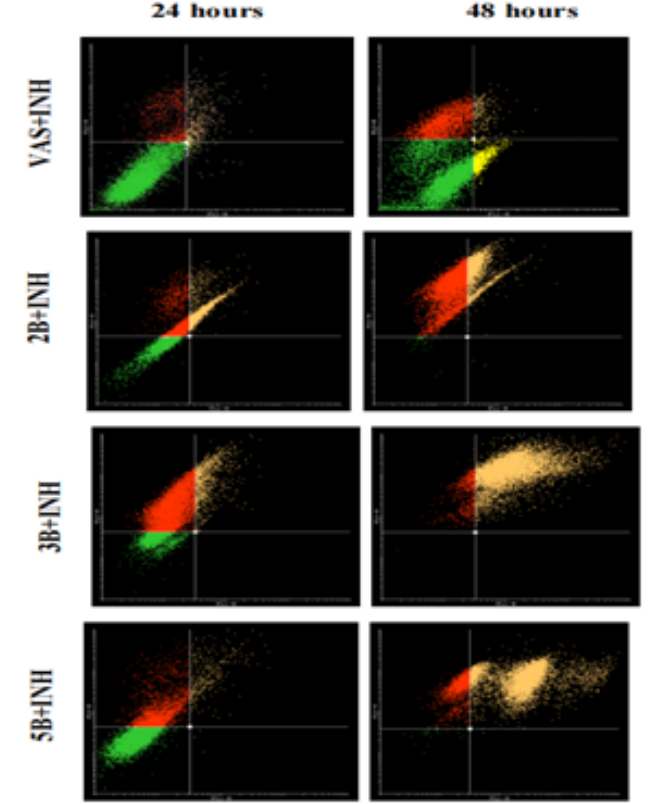

\section{Figure 5}

Figure representing the Dot plot, obtained upon subjecting the BCG infected THP1 macrophages upon treating with (A) isolated compounds and (B) compounds along with INH. PI (Propidium lodide) and Annexin V FITC staining were done to evaluate apoptosis and necrosis. Lower Left quadrant represents live cells (green), Lower Right quadrant represents early apoptotic cells (Annexin V stained, yellow), Upper Right quadrant represents late apoptotic cells (stained with Annexin $\mathrm{V}$ and $\mathrm{PI}$, orange). Upper Left quadrant represents necrotic cells (PI stained, red). 


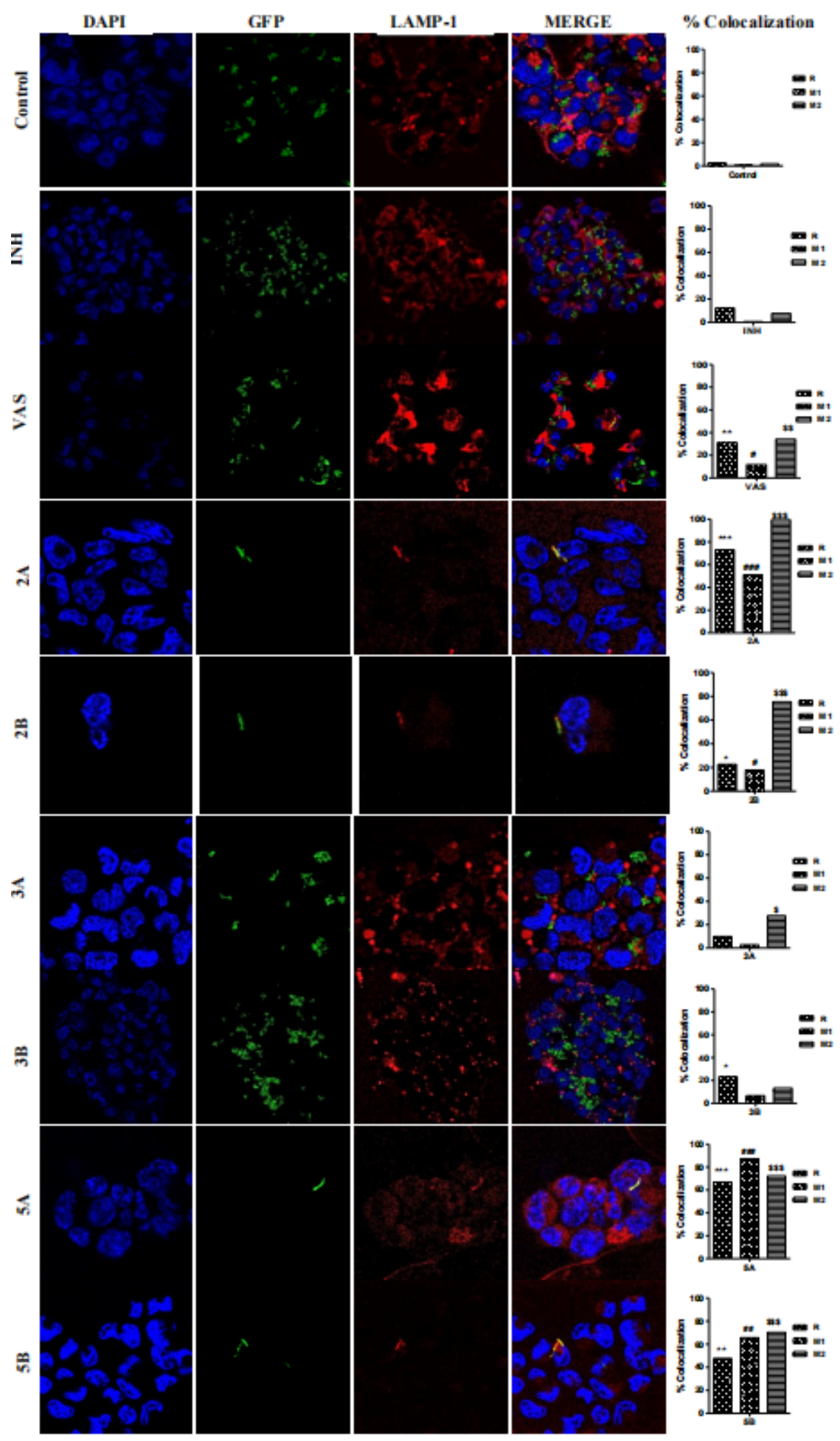

\section{Figure 6}

Confocal imaging of BCG-infected THP1 macrophages treated with fractions 2A, 2B, 3A, 3B, 5A, 5B, and Vasicine, compared with Control (untreated macrophages) and INH. DAPI stains THP1 nucleus in blue, GFP is expressed by internalized BCG, and Lysotracker Red is used to stain LAMP-1 proteins present on lysosomes. Merged image is used to identify and measure colocalization using ImageJ application. Percent colocalization (R), red overlap (M1), and green overlap (M2) is showed in adjacent graphs. *p value $<0.05$, ${ }^{* \star p}$ p value $<0.001,{ }^{* *} \mathrm{p}$ value $<0.001$; t-test result compared to Control for \% colocalization. \#p value $<0.05$, 
$\# \#$ value $<0.001, \# \#$ \# value $<0.001$; t-test result compared to Control for $\%$ red overlap. $\$ p$ value $<0.05$, $\$ p$ value $<0.001, \$ \$ p$ value $<0.001$; t-test result compared to Control for \% green overlap.

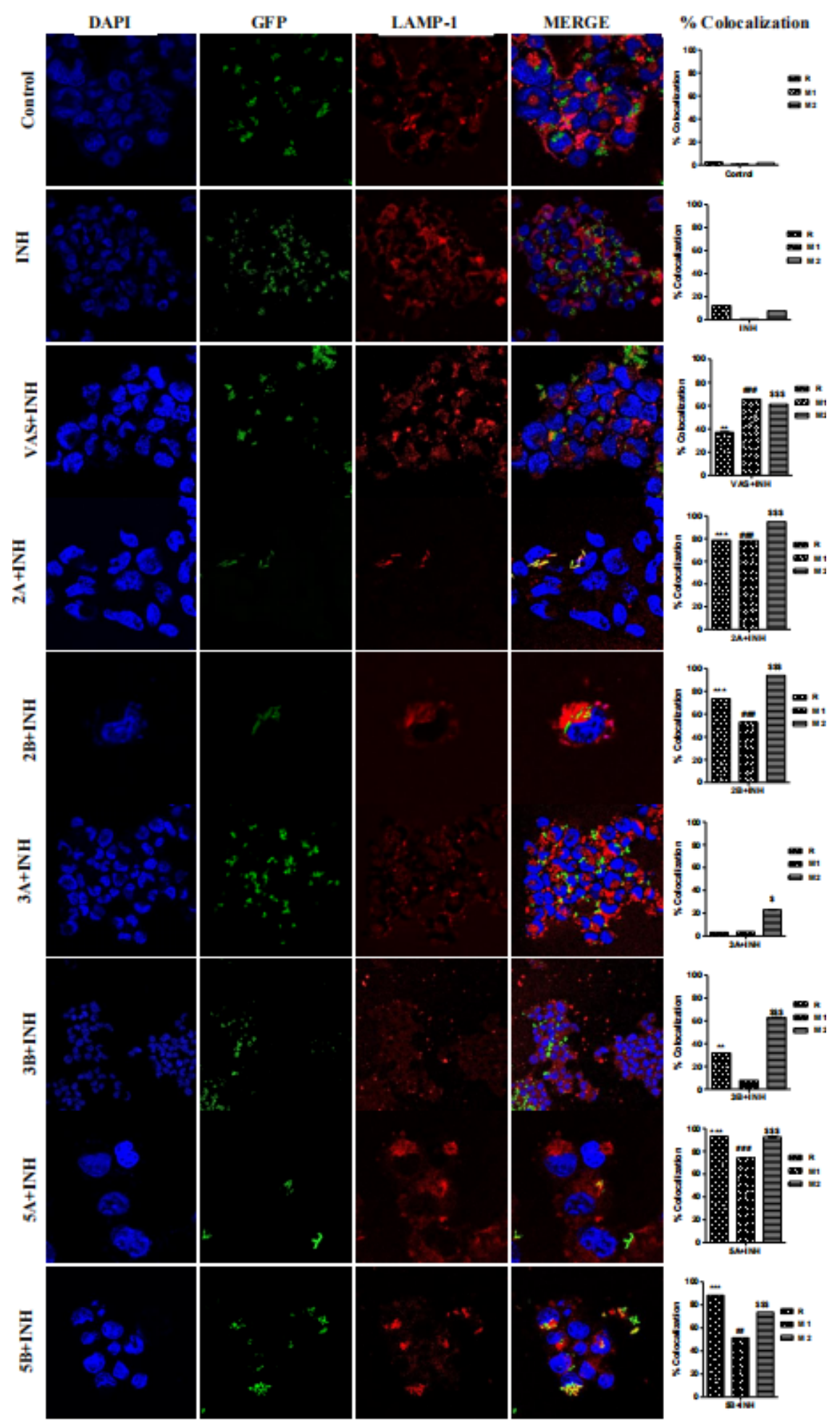

Figure 7

Confocal imaging of BCG-infected THP1 macrophages upon co-treatment with INH and fractions 2A, 2B, 3A, $3 \mathrm{~B}, 5 \mathrm{~A}, 5 \mathrm{~B}$, and Vasicine, compared with Control (untreated macrophages) and INH alone. DAPI stains THP1 nucleus in blue, GFP is expressed by internalized BCG, and Lysotracker Red is used to stain LAMP-1 proteins present on lysosomes. Merged image is used to identify and measure colocalization using ImageJ 
application. Percent colocalization (R), red overlap (M1), and green overlap (M2) is showed in adjacent graphs. ${ }^{\star} p$ value $<0.05,{ }^{\star *} \mathrm{p}$ value $<0.001,{ }^{\star \star *} \mathrm{p}$ value $<0.001$; t-test result compared to Control for $\%$ colocalization. \#p value $<0.05$, \#\#p value $<0.001$, \#\#\#p value $<0.001$; t-test result compared to Control for $\%$ red overlap. $\$ p$ value $<0.05$, $\$ p$ value $<0.001, \$ \$ p$ value $<0.001 ; t$-test result compared to Control for $\%$ green overlap.

\section{Supplementary Files}

This is a list of supplementary files associated with this preprint. Click to download.

- SupplementaryData.docx 